\title{
Study on the Source of Creative Thinking of Ancient Purple Sand Tea Sets
}

\author{
Jin Xiang ${ }^{1}$ \\ ${ }^{1}$ Wuhan Institute of Design and Science, Wuhan, 430062
}

Keywords: ancient purple sand tea set; design thinking; source

\begin{abstract}
The people-oriented design, political conditions and social backgrounds produce a design concept that meets the development of the times. The origin of this design concept is cultural and environmental, and other crafts legend has created it not out of thin air. As for the source, how to further develop the craftsmanship is the purpose of this paper on the ancient traditional purple sand art. The development of ancient purple sand craftsmanship is a proof of several hundred years of practice. The advantages and disadvantages of this practice can be directly exposed by the research. As long as the intention is summarized, it can be found that the development of this craft is not an isolated region that has been mythized by contemporary people, and its development is based on the humanities at that time, regional culture, integrated with a variety of techniques, combined with social backgrounds of different periods, reflecting the results of social and cultural needs, and there is a design thinking on modeling and aesthetic choice in the late Qing Dynasty. The different kinds of decorative styles of teapots exported to Europe and Southeast Asia indicate that the design thinking at that time was not beyond imagination. Demands, methods, and humanities should be the main sources of thinking. This paper analyzes the development of the history of purple sand tea sets and protect traditional molding techniques as a precondition to provide a feasible direction for the creation and development of contemporary purple sand tea sets.
\end{abstract}

\section{The Origin of Purple Sand Tea Sets}

Zisha is a natural ore, a collective name for purple clay, green mud, and red mud. Its metallogenic age has already reached 100 million U.S. billion. It is produced in Huanglong Mountain and Qinglong Mountain in Yixing, China. The source of this material has not yet been found in other regions of China or in other parts of the world. So the raw material itself is already extremely precious.

Zisha tea sets are produced in Yixing and mainly produce teapots for making tea. At the earliest time in history, there was controversy in the area of Chinese art research and archaeological research. According to historical records that can be checked, the reason why the purple tea set will appear is because of the relationship between weather, geography, and people. It can be understood that the promulgation of the ordinance of converting tea from tea to tea in the early Ming Dynasty was regarded as the time of day. The advantages of Yixing's native purple sand material are regarded as geographical advantages, and the craftsmen began to timely create human beings in order to meet the demands of the decree. The simultaneous satisfaction of these three conditions led to the birth of Zisha tea sets. Because of the plasticity of the material and the uniqueness of its production methods, it allowed it to integrate the styling and extension of bronze ware, jade ware, lacquer ware, stone sculpting, and porcelain styling. Therefore, it has become an important special technological heritage in the history of Chinese art and culture.

\section{The Origin of the Creative Thinking of the Ancient Purple Sand Tea Set}

Starting from the beginning of the Zisha tea set to delineate the time range of an ancient development, it was the Ming and Qing Dynasties of China, that is, from 1368 to 1911, it took about 543 years. According to the definition of the earliest unearthed cultural relic at present, the Zisha tea set can be temporarily designated as the middle of the Ming Dynasty, that is, between 1471 and 1533. In the existing Nanjing Museum of China, the pot is thick and simple in shape. 
Afterwards, some Ming Dynasty purple sand tea sets have been unearthed. They all belong to the middle and late Ming Dynasty. Combined with historical records of the purple sand monographs, the whole period of Ming and Qing Dynasties was designed in various stages. The division of the birth of thinking can be divided into six major phases, namely the middle Ming Dynasty, the middle and late Ming Dynasty, the late Ming and early Qing Dynasty, the early Qing Dynasty, the middle Qing Dynasty and the late Qing Dynasty.

Although the purple tea set unearthed in the middle of the Ming Dynasty was the first one, this issue has always been controversial in China's purple sand research field. However, whether it was first or not, it appeared on September 16, 1391. The tea tea that was born after the group's tea reformed leaf tea was designed to meet the requirements of the government ordinance, to discard the tea drinking method, and to use the teapot design produced when drinking tea. At the same time, it is necessary to point out that it is at this time that the purple sand mud is being poured out from ordinary clay. It is precisely because the immaturity of the initial stage of the refining process, and that the quality of the purple sand that was unearthed in the middle of the Ming Dynasty is thick, not The fineness in our concept. In addition, the special nature of the purple sand material itself makes it grow. Its advantages are: 1 . Zisha is the collective name of the three kinds of slime, these three kinds of raw materials can be formed independently, but also can be matched with each other, and the proportion of different combinations will show rich color changes. 2, purple sand material contains quartz, hematite, mica and other agglomerating substances, in the 600 times the microscope, you can see the unique double pore structure, making it breathable water, so the tea will no longer pot Bored bad. 3, Zisha compared with china clay, the shrinkage is small, plasticity is high, not easy to be deformed, so the precision of modeling is high. At this point, with the help of weather, geography, and people, under the premise of satisfying daily life, Zisha tea sets began to develop in Yixing.

\subsection{Use of Ming Dynasty Materials and Reference of Porcelain Burning Process}

The mid-Ming Dynasty records in the Ming Dynasty were the initial stages of Zisha tea sets, referring to the dates from 1391 to 1586, but the written records were not very rich. There were only six records of famous artists, so one can imagine the development platform at that time. Not open. However, there are four points that must be mentioned. The tree tumor pot that imitated the creation of natural forms in this period represents the thinking of the design of the shape of the original teapot. 2. Liang Liang, one of the six celebrities who wrote records, pioneered the style of the Bai Liang pot, demonstrating the artist's idea of trying to create the advantages of the purple sand material. 3. There are six famous artists recorded in the records, including one from Jiangxi Wuyuan, not Yixing native, named Li Maolin. The records of records from Li Maolin, Zisha firing began to use the enamel roasting process, therefore, the purple sand firing farewell to the past and the cylinder with the burn, the surface of the glaze tear, the firing process has made innovative progress. But in fact, this set of burning process was not created out of thin air, because the distance between Jingyuan Town and the China Porcelain Center was very short. At that time, Jingdezhen's firing of porcelain had already been used in the firing process. Therefore, this process can be applied to the process of burning purple sand, is the inevitable result of reference porcelain process. 4 . At the beginning of the family heritage, Shi Peng, one of the six people, was the only entertainer whose historical records inherited the production process to his posterity. His son Shi Bin was the icon of the Golden Age that led the development of the tea industry in the middle and late Ming Dynasty.

\subsection{Concept of Class Design by Class in the Ming Dynasty}

The middle and late Ming Dynasty referred to the period from 1586 to 1644, which was a golden period for the development of the Ming Dynasty teaware. The reason why this is the golden period is because this period not only enriched the design thinking and modeling style of the purple tea set because of the integration of local crafts, but also opened the development platform for Yixing Zisha tea set. The leader of this era is the son of Shi Peng, the famous purple sand master in the middle of the Ming Dynasty. This time, other famous craftsmen were all disciples or juniors. According to historical records, Shi Bin was originally named after the spring pottery, and 
afterwards he got the literary person's instructions and began to create a small pot suitable for the literati's aesthetics, thus creating a new era for the Zisha Tea Set. The literary person who directed him is a personage in Shanghai today. Shanghai and Yixing are separated by more than 200 kilometers. This record can illustrate two points. 1. Shi Bin's pot art creation is famous for its copying, but it does not obstinately follow the Yixing antique model. Instead, it takes its origins and communicates with high-level literati's thinking to obtain creative directions that meet the aesthetic needs of the class. Therefore, in Shi Dabin's purple sand works, purple lacquerware tea sets that met the Ming Dynasty court aesthetic appeared. Zisha tea sets from the civilian civilian device into the palace imperial device, the integration of lacquerware and purple sand has fundamentally improved the artistic value of the teapot. Zisha tea set into high-end display platform. 2. The Yixing local Zisha tea set was originally designed to meet the needs of civilians for daily use. Therefore, it is a practical pot. The shape and decoration are simple and not too elaborate. The literati pays attention to the elegant taste and aesthetically prefers the elegant styling. This has prompted Shi Bin's creation of purple sand tea sets, which needs to be treated differently in terms of form, decoration, and size. This is aimed at different groups of people. The design thinking created the direction of the development of Zisha tea sets in the Da Bin era.

\subsection{Ideas of Integration of Other Regional Techniques in the Ming Dynasty for the Development of Foreign Platforms}

No matter how the shape changes or the pattern of decoration that meets the requirements is not a fantasy, the ancient thinking exchanges and communications are not advanced. Only by the power of Shi Bin, at the time the economically underdeveloped Yixing, regardless of manpower, Process maturity or sales platform, this kind of fine and lasting development is very difficult to do. Only a region with advanced and prosperous economy can gain a platform for development. However, when Dabin was invited to the Ziyuan Xu family to make a purple tea set, it was a perfect opportunity for development.

During the Ming and Qing dynasties, China's Huizhou merchants were very large. They led the economic prosperity of the entire region of Jiangsu and Zhejiang. Its center was in the area of Wuyuan County in Jiangxi Province. At this time, the "three carvings" craftsmanship of Wuyuan was a period of prosperity. Every household in Wuyuan was flooded. With wood carvings, stone carvings, and brick carvings, the contents include flowers, birds, fish, insects, beasts, and figures. The craftsmanship includes carvings, openworks, bas-reliefs, and engravings. The development of the commodity economy leads to all parts of the country. It was this perfect opportunity for Shi Dabin to widely receive his disciples and complete the inheritance and development of Zisha Tea Craft. It also provides a good sales platform that can lead to everywhere. The most important thing is that his disciples have combined the "three-sculpture" craftsmanship with the creation of the Zisha tea sets, and have completed the long-term advancement of Zisha tea set modeling and decoration techniques. Let the purple tea set in this period open up the market and there will be a pot of hard to find. As a result, the number of records of celebrity tea sets recorded in the ancient book record reached 24th. In contrast, the development of purple sand tea in the early Ming Dynasty was only 6 artists in 185 years, while in the middle and late period only 24 masters appeared in 58 years, showing rapid development.

\subsection{The Ideas of Creation and Imitation in the Ming Dynasty}

Before the advent of the purple sand process, many other Chinese crafts have flourished, including bronze crafts, porcelain crafts, lacquer crafts, jade carving crafts, stone carving crafts, brick carving crafts, wood carving crafts and bamboo carving crafts. These crafts started early in Chinese history. Modeling and decorative techniques have developed quite well. In economically developed regions, the circulation in the market has been seen everywhere, high-quality boutiques or antique collections of large families, often invited. Show. So people have the conditions to watch these beautiful works of art. The purple tea set in this period, regardless of craftsmanship or styling thinking is still a start-up position. At this time, the major purple sand masters are all disciples of Shi Bin. In addition to one of his disciples, the other seven were all from Jiangxi Wuyuan. At this 
time, Jiangxi Wuyuan flourished in economy and there was a continuous stream of excellent business contacts. Therefore, it is an inevitable result to learn from the most prosperous shape on the market to develop Zisha teaware style.

Looking at classics, we can see that at the same time, most of the purple-scented artists are known for their works in copying the works of Da Bin and his apprentice. On the one hand, it can explain the bias of the market demand for purple sand at that time, resulting in artists mimicking the works of famous artists to meet their living needs. On the other hand, it is not easy to learn the skills of the famous purple sand artist, and it is also the most direct way to improve the craft by imitating celebrity works. Just as modern people learn to paint, they must be copied first. In the process of imitation can be found and learn the details of the processing method, but such an approach will also limit the development of purple tea. It also caused confusion in modern research. After 500 years of separation from the precise imitations of the same generation, we were unable to distinguish the famous masterpieces. Fortunately, at the same time, the imitations of the ancients mostly followed the physical copying, so the famous pottery form should be completely preserved, and still provide evidence for our study of the art form.

\subsection{The Artistic Leap of Purple Sand Tea Sets in the Qing Dynasty - From the Participation of the Literati to the Leading Design}

The political situation in the early and mid-Qing Dynasty was stable, and the economy was prosperous and prosperous. In particular, various handicrafts in the Jiangnan region had achieved unprecedented development. Zisha tea sets have entered the state of developing artistic masterpieces in the main direction of Ming dynasty craftsmanship, and have entered the state of developing the level of artistic taste. Zisha tea sets have officially entered the field of art work from daily life supplies.

Inheriting the ideas and techniques of the Ming Dynasty's predecessors, the development of the Zisha tea set in the Qing Dynasty has entered an unprecedented period of prosperity. With the concept of hierarchical design, Zisha tea sets have gained more favor among middle and high-level literati and clans in the masses. The nobles invited the famous purple sand masters to make teapots at home, or to go to Yixing local and custom teapots. This private custom approach became the literary and scholarly style of the time. These literati and scholars are famous for their paintings and paintings, and they are famous for their carvings and stone carvings. Therefore, their aesthetic concepts must have a significant influence on the artistic taste of teapots. In the early period of this time period, literati participated in the making of pots, engraved with poems on the pots, and deposited funds. After the literati designed the pot-like drawings in the middle period, the purple sand masters were invited to customize the situation. From the participation of the literati to the leading design, this process has led to a qualitative leap in the artistic level of the tea set.

\subsection{The Innovation of Purple Sand Tea Set Decoration Techniques in Qing Dynasty}

The court's imperial craftsmanship has always been based on high standards of exquisite craftsmanship. Under the influence of the gentry fashion, the courts of the Qing Dynasty also began to accept bare-boned zisha tea sets, but they have always felt that they were not sufficiently refined and did not meet the royal style. So, during the Kangxi and Yongzheng eras, the European enamel technology was used to decorate the Zisha teapot. Because Eucalypt raw materials are produced in Europe, the prices are high. Therefore, it cannot be used on a large scale. Therefore, there is not much production at the royal court, and it is even more impossible for people to circulate. In order to use this kind of decoration technique, it later changed to the pastel process used in Jingdezhen porcelain production. Because the raw material is produced in China, it is easy to be promoted. Therefore, this kind of decoration technique has been popular in the court both inside and outside. However, the full-color or spot-colored decoration of the teapot always erases the original rhyme of the purple sand, and it loses the advantage of breathability and is not practical. Therefore, this kind of decoration technique has not passed the test of practice, and it is eliminated after the fresh period expires. In addition, during this period, the court also saw the process of enchasing the snails in the Zisha pot paint, and the gold lacquer painting process, but in the end, it was only because of its 
ornamental nature and practicality. Therefore, these four kinds of crafts basically only exist in the palace and are used by the emperor.

\subsection{The High Requirements of the Design of Folk Purple Sand Tea Ware in Qing Dynasty}

The representative of Seiko in the Qing Dynasty should belong to Hui Mengchen. He can serve as a Seiko representative mainly because he created a small teapot equal to the modern proportion standard from his hands. This small purple teapot is the originator of Fujian Kung Fu tea in China. This fine jug is called a horizontal jug. It is characterized by the fact that the user can hold pots with one hand, and the spouts and pots balance the proportional weights on both sides. At the same time, they follow the consistent standards of the teapot. The lids are tightly closed and the drops do not leak. Therefore, when the teapot is filled with hot water and the pot is placed on the still water surface, the pot body will not be tilted. Instead, it will use the buoyancy of water to float on the water surface. Therefore, drinking tea with this pot, modern people gave a nice name called "Kung Fu Tea." The shape of the horizontal pot is not one type, but there are many kinds of it, which indicates that the creator is exquisite in craftsmanship. This pot is not only popular in Fujian Province, China's home of tea drinking. Historical records indicate that in the second half of the 17th century, a large number of teapots with Huimengchen names were exported to Portugal and other places. They are also very popular in European countries. Therefore, at the same time, there are also many zisha entertainers who copy the Hui Mengchen level pot. This gravity-balanced design concept and high-precision requirements created a lot of influence at that time. Another representative is Chen Mingyuan. His work is characterized by the use of color matching to achieve the ultimate in color matching of purple sand raw materials. He was the first master to use a variety of colors to make a teapot. It is also the first person to create various parts of the pot body in various plant shapes. Qing literati and gentry scrambled to invite him to make teapots at home. Therefore, there are also many people who copy his works at the same time. Because of his design concept and the influence of Seiko, he is now a model for promoting the development of teapot in the Qing Dynasty.

\subsection{The Concept of Decorative Decoration of Purple Sand Tea Sets in Qing Dynasty}

Yixing Zisha, Europeans called it "red porcelain", the Portuguese merchant ships brought it to Europe at the end of the Ming dynasty, and at this time the teapot won a high reputation in Europe. During the Qing Emperor Kangxi years, overseas trade was frequent. During this period, Europeans introduced the aesthetic elements of Chinese crafts into their own craft system. As a result, the "Chinese taste and Chinese style" culture spread throughout Europe. At the same time, the taste of European decorations has also adversely affected China's Zisha tea sets.

Europeans in the 17th century were not sensitive to the shape of teapots. They paid more attention to surface decoration. Therefore, custom teapots exported to Europe during this period were mostly decorated with decals or enamel carvings. From the pot size, exports were small. This is because at the time the tea prices on the European market were high, and the small-capacity teapots could reduce the amount of tea used, so the small pots were more popular in Europe, and because of the Europeans' determination of the color of red porcelain, the export of the red teapots, Zhu mud pot is the most common.

Compared with the Chinese literati's preferences at the same time, the Qing Dynasty's export teapots have a variety of decorative styles, such as embossing, decals, enamel carving, inscriptions, embossing, pastels, spot colors, etc., but the decorative patterns are still The traditional "Mei, Lan, Zhu, Ju" four gentlemen, retains the style of Chinese culture, while meeting the European aesthetic needs. In addition, export trade with other countries such as Thailand has also had a mutual influence. After the Thai royal family customized the Zisha teapot, it was re-decorated, or polished the surface of the pot to the mirror light, or used in the spout, pot, pot lid gold, silver decoration, luxury. This style of decoration also affected the appearance of the purple sand decoration in the same period in China. 


\section{Conclusion}

The design ideas of ancient zisha teapots ranged from the reference to natural forms to the imitating of popular bronze ware, porcelain and other ancient artifacts, to fusion jade, lacquerware, tin-wrapped, gold-clad, and silver-clad. The development of purple sand decoration is based on the techniques and content of stone carving, wood carving and brick carving. The Zisha Teapot was not known from the middle of the Ming Dynasty and was sought after by the world during the mid-Qing Dynasty. It has been quite active for more than 500 years. The development model has not adopted the strategy of self-research in closed doors in Yixing, but has adopted the development of a regional platform for borrowing economical wealth. It can also adjust the style of decoration according to the needs of different levels of the market and adjust the style of decoration to meet different aesthetic tastes. Its variable shape coupled with a wealth of technology, coupled with the rare and breathable purple raw material itself, creating a purple sand teapot is a rising star, but the price is much higher than the status of similar teapots. Until the late Qing Dynasty, during the early years of the Republic of China, due to the frequent wars, the purple sand artists stepped around and the artistic development of the Zisha teapot process was stagnant.

After hundreds of years of development, the Zisha teapots of the Ming and Qing dynasties are now valuable antiques and are sought after by many collectors. The collection is a good thing, but behind the high prices, the museums in China do not show the Ming and Qing dynasties. The collection of zishaware in kind, because any size and details of the leak may make imitation goods come out as genuine products, under the lure of high profits. A large number of local pot makers in Yixing have been hired by high-paying merchants to imitate famous products. This phenomenon needs to be viewed from two perspectives. On the one hand, imitation also includes the inheritance of constant flavor, which has positive significance. But on the other hand, cheating on profits from modern art as an ancient art is actually the seed of deceit for the later generations. How desolation will it be for the Chinese children and grandchildren in the future to be unable to distinguish the remains of historical achievements?

Zisha pottery is unique to China. Like the giant panda, it has the uniqueness of the native, the uniqueness of the cultural connotation, and the uniqueness of the esoteric method inherited from the craft, and it is also a non-renewable resource. Therefore, for all human beings, the protection of China's zisha culture should be global, but first, we should start from us to protect the raw materials of zisha, and we must also protect the time characteristics of cultural heritage. Zisha art is the longest historic human creation. Unique practical works of art can protect the time characteristics of human beings and leave a complete historical site for the development of purple sand.

\section{Acknowledgements}

Fund Project: 2016 National Social Sciences Fund Project 16BA009 Research Achievements of the "Research on the History of the Zisha Art in the Ming and Qing Dynasties"

\section{References}

[1] Lu Yu, Tea Sutra, Zhonghua Book Company, 2010

[2] Wen Zhenheng, "Long Things", Zhonghua Book Company, Ming Dynasty, 2012

[3] Han Qilou, “Fortune Teapot”, Fujian Fine Arts Publishing House, 2001

[4] Zhu Quan, Tian Yiheng, “Tea Scores, Cooking Springs Pieces”, Zhonghua Book Company, 2012

[5] Xu Zhiheng, “The Porcelain of Drinking Streams,” Zhonghua Bookstore, 2012

[6] Zhao Jianqi, Zisha Hu Collection Appreciation, China Federation of Industry and Commerce, 2015

[7] Zhou Gaoqi, “Yangshuo Hushu System. Gu Dong Thirteen”, Zhonghua Book Company, 2012 
[8] Chen Lihua, "Law Detected", Guangxi Normal University Press, 2002

[9] Yan Keqin, “Xian Gu Buddha Heart - Furniture Zisha and Ming and Qing literati”, Life, Reading, Zhixin Sanlian Bookstore, 2011

[10] Xu Xiutang, Purple Craft, Shanghai Ancient Books Publishing House, 2014

[11] Chief Editor Wang Jianhua, Collection of the Forbidden City, Forbidden City Press, 2007

[12] Han Qilou, “Chinese Zisha Teapot Review”, Shanghai Science and Technology Press, 2014

[13] Patrice Wanfulai, "Yixing Teapot Sold to Europe", Xiling Yinshe Press, 2015

[14] Chinese Silicate Society, History of Chinese Ceramics, Cultural Relics Publishing House, 2010

[15] Red Sandalwood, China Zisha Culture, Current Affairs Press, 2014

[16] Yang Zifan, “Implication of Zisha: Yixing Zisha Technology”, Zhonghua Book Company, 2013

[17] Zisha Pottery Modeling, Qing Gong Press, 1957

[18] Hong Kong Tea Culture Museum "Yixing Zisha Pottery", Hong Kong Museum of Art, 2012

[19] Xu Yurun, "Xu Haorun's Purple Clay Pottery Collection", Tang Press, 2010

[20] Wu Shan, China Zisha Dictionary, Jiangsu Fine Arts Publishing House, 2007 